\title{
RETHINKING OF THE RELATIONSHIP BETWEEN AGRICULTURE AND THE “URBAN” ECONOMY IN BEIJING: AN INPUT-OUTPUT APPROACH
}

\author{
Zhenshan YANG ${ }^{\mathrm{a}}$, Jianming $\mathrm{CAI}^{\mathrm{a}}$, Michael DUNFORD ${ }^{\mathrm{a}, \mathrm{b}}$, Douglas WEBSTER ${ }^{\mathrm{c}}$ \\ anstitute of Geographical Sciences and Natural Resources Research, Chinese Academy of Sciences, \\ 11A Datun Road, Anwai, Chaoyao District, 100101 Beijing, China

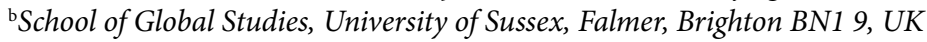 \\ 'School of Politics and Global Studies, ASU, PO Box 873902, Tempe, 85281 Arizona, USA
}

Received 19 January 2012; accepted 14 April 2012

\begin{abstract}
Despite the irresistible drive of urban growth, the questions as to whether and how agriculture is restructured and repositioned in relation to urban development have received little attention. Based on the method of hypothetical extraction from input-output tables, and on the Beijing case, this paper puts forward an approach to assess the dependence of the agro-economy on urban sectors. The research shows that in Beijing in the period from 1982 to 2007 the relationship between agriculture and the urban economy has gone through three phases. At the start of the economic reform, the relationship was weak, characterised by intensive inputs of agricultural productive materials and policy orders. What followed was a phase of disconnection characterised by fast urban growth and low competitive status of agriculture. The third was a period of increasingly integrated development with technological inputs and upgrading of the management of agriculture. The current strong relationship indicates that agriculture can be tuned to meet the preferences of urban consumers. Key associated urban sectors are screened out to verify this relationship. The approach is valuable for quantifying the structural relationship between agriculture and urban sectors, for further analysing rural-urban economic relationships to support development policy design and programming.
\end{abstract}

Keywords: agriculture, urban economies, input-output analysis, hypothetical extraction method, rural and urban development, Beijing.

JEL Classification: A12, C15, C80, O13, O18, P11, P25, Q10, R15.

Corresponding author Jianming Cai

E-mail: caijm@igsnrr.ac.cn 


\section{Introduction}

Agricultural or rural development may struggle to adapt to the process of urbanisation, in particular in developing countries. For example, China has achieved spectacular economic and urban growth in the past 30 years, and yet the development status of agriculture is relatively weak, and the disparity between the rural and urban has become larger and larger (Liu et al. 2008). This situation is due to the low economic returns to agriculture, but is also profoundly influenced by conventional dualistic thinking about urban and rural development, which limits the promotion of agriculture in urbanised societies. A key question, not yet fully addressed, concerns the extent to which agriculture, as a fundamental driver of rural development, is dependent on "urban" economies and their growth: researchers and practitioners in particular remain unclear about the impact of urban development on agriculture. This paper presents an approach, based on Input-Output (I-O) analysis, for assessing the dependence of agriculture on "urban" economies (proxied by urban sectors) and applies it to the case of Beijing.

The interdependence of agriculture and urban economies is often under-emphasised. Formerly rural and urban areas were viewed as two separate economic systems, with few interactions (Higgins 1956; Hirschman 1958; Tacoli 1998; Bezemer, Headey 2008). Agriculture was accordingly guided and developed with little reference to urban economic activities. As a result, agricultural capital accumulation and growth was based primarily on internal linkages and multipliers, with the result that its innovative transformation was constrained. In these circumstances, it was difficult to revitalise rural areas. Rural decline often seemed an inevitable process, evident in many regions (Rutten, Boekema 2007; Markey et al. 2008). Agriculture also loses its attractiveness for both producers and consumers. Many famers leave their land, and citizens do not know where their food comes from. Farmland, especially around the edge of cities, is transferred to urban uses, creating (potential) challenges for environmental sustainability and food security.

Recently, a growing body of literature documents the (re-) connecting of agriculture and urban economic activities, including the development of agro-tourism, the deepening of agro-processing and the rise of local food networks (often involving high value agricultural products, e.g., organic fruit and vegetables) that closely link agro-food and the urban market (Marsden et al. 1999; Goodman 2004; Wilson 2007). Some of these activities have emerged in Beijing. Agro-parks, for example, have become a destination for the recreation of citizens (Yang et al. 2010). The ever increasing popularity of these types of agro-activities implies a rapid change of the economic relationships between agriculture and urban development, crying for new types of policy geared towards the promotion of agriculture and the further integration of urban-rural development.

This dependence of the agriculture on urban sectors is influenced and mediated by complex economic, social and institutional processes and factors. The OECD (1996) indicated that rural development is determined by a set of specific regional and local factors. These economic and social factors include rural standards of living, entrepreneurial tendencies, traditions, public and private networks, work ethic, regional identity, the quality and attractiveness of the cultural and natural environment, demographic dynamics and migration trends, and the 
social value attached to the rural idyll and rural lifestyles. Agriculture is moreover one of the sectors most strongly influenced by governments, through, for example, price subsidies and the protection of farmland. Institutional factors can also stimulate new agro-activities. Although it might not be good in conventional economic terms to cultivate agriculture in urban fringes, the growth of peri-urban agriculture is driven by multi-purpose use for the city including food production, recreation, and green space, which draw attentions from urban planners (FAO 2007). Deriving from the combination of food and environmental functions, multifunctionality in agriculture is quickly developed in Europe with the support of the Common Agricultural Policy of the European Union (Morgan et al. 2010).

Assessing the dependence of the agro-economy on urban sectors is complicated. Although a number of useful studies have identified the linkages between these two sectors (Adeyemi 2000; Wilson 2008; Holmes 2009), there is little quantitative analysis concerning the relationship. To help fill this gap, this paper focuses on the structural dependence of agriculture on urban economies and systematically investigates it by means of the Hypothetic Extraction Method (HEM) of Input-Output (I-O) analysis. This approach is tested in Beijing Municipality. This Municipality considerably over bounds the built-up urban area. A majority of the land area is rural, providing an area to examine and analyse the relationship between structural change in agriculture and the development of the urban market.

More specifically, the paper addresses three questions: (1) To what extent does agriculture as a whole depend on urban sectors?; (2) what urban industries are most closely related to agriculture?; and (3) how do internal relationships within the agricultural sector change with urban development? To our knowledge, this paper involves the first attempt to apply I-O analysis in a study of the relationship between agricultural and urban development.

The rest of the paper is divided into four sections. The next section reviews and discusses the industrial linkages between agriculture and urban sectors and assesses the usefulness of I-O in examining these relationships. The third section deals with the specific context examining the relationships between the agro-economy and urban development in China, particularly in the Beijing Municipality. In the fourth section, the use and relevance of HEM in measuring the dependence of agriculture on urban economies is elaborated. The fifth section presents the results of our I-O analysis. The paper concludes by discussing the changing of agriculture with the urban development, and the role of the method deployed, as a decision support tool to facilitate policy analysis oriented to furthering promotion agricultural development.

\section{The case for identifying agriculture-industry linkages utilizing Input-Output methods}

Despite some negative impacts of urban development on agriculture such as the loss of farmland to urban uses, the rapid advance of technologies and information systems has increased the possibilities for agricultural development (Marsden et al. 2002; Ortiz-Miranda et al. 2010; Liu, Zhang 2011). With urban development, agriculture experiences profound structural transformation. This process includes the deepening of agriculture-industry value chains, the integration of agro-production with non-agro activities, the re-ordering 
of agricultural production through farm labour relocation and the reorganisation of rural resources (Ortiz-Miranda et al. 2010).

Examples of urban-market induced structural change include urban agriculture and multifunctional agriculture (Holmes 2006; Mougeot 2006; Evans 2010; Mawois et al. 2011). Agro-tourism, for example, as one of the main forms of urban agriculture, combines agriculture and tourism to increase agricultural incomes and revitalise rural areas (Yang et al. 2010). Food processing becomes more and more sophisticated as its chain is extended to produce customised products (Donald, Blay-Palmer 2006). These new forms of agricultural development indicate how the development of urban markets provide external sources of agricultural income and how agriculture and urban areas can have intrinsically strong connections. A deepening and strengthening of agriculture's local economic interactions could make its development more sustainable (Winter 2003).

These findings, usually based on case-studies, however only document a part of the changes in agriculture that accompany urban development. The overall relationship between agriculture and urban economies remains unclear. In the face of rapid urbanisation, Hoggart and Paniagua (2001) argue for a holistic analytical approach to examine changing agricultural processes. As structural change and new forms of agriculture are closely related (Noguera-Méndez, Semitiel-García 2011), functional structural analysis may help understanding changes in the relationship between agriculture and urban development. Through the multiplicative process, or namely ratios, the efficiency of one sector's development can be more appropriately estimated and the sector can be better positioned within the economic system in decision making (Brauers, Zavadskas 2010).

There are opportunities to improve the economic performance of agriculture if agriculture can increase value added through its closer articulation with non-agro sectors. At present, however, there is a research gap when it comes to identifying the key supply-chain relationships. One recent contribution addressing this research gap is the work of Noguera-Méndez and Semitiel-García (2011). Their work examines the embededness and network characteristics of agriculture in the industrial system, and identifies "core" relations of agriculture with certain sectors by means of social network analysis using national I-O data for Spain. It is rare however to see an analysis of the economic flows between agriculture and urban sectors for a city/region, and therefore current research cannot adequately support the design of strategies for agricultural development in urbanised societies. As Meijerink and Roza (2007) argue, many failures in agricultural and rural development derive from the fact that they ignore or fail to put sufficient emphasis on the role of non-agricultural sectors, and their synergies with agriculture.

To examine these interdependencies at a macro- and a regional-scale this research draws on an Input-Output (I-O) approach, as it can capture inter-sectoral relationships for an entire economy. I-O linkages are a useful tool to identify the unanticipated impacts of sectoral policies (Noguera-Méndez, Semitiel-García 2011). The I-O approach permits a more comprehensive identification of changes in the relationships between agricultural and urban supply chains than case studies. In addition, I-O analysis facilitates an understanding of changes in industrial linkages, which can stimulate innovation in agricultural development, by recombining and reconfiguring resources to create outcomes adapted to the 
urban market (Goodman 2004). For example, exogenous factors could be introduced into agriculture, shifting agriculture from "a homogeneous agricultural commodity market to a more segmented market” (Winter 2005: 506). As marginalised rural areas may be unable to cultivate speciality foods (Winter 2003), technological and managerial innovations that reduce marginalization and increase interdependence are crucial for the economic growth of agricultural sectors (Clark 2006).

\section{Research case study context: Beijing and the transformation of Chinese agriculture}

China has been experiencing dramatic economic and urban growth since the start of economic reform in 1978. This rapid change initially occurred in the context of a dualistic urban-rural structure, which lead to rather different processes for urban and rural development. In contrast to the increasingly high profile of urban development, the performance of agriculture remained relatively weak. Adjusting the structure of agriculture has increasingly been advocated by policymakers to counteract rural decline, in particular by increasing farm profits and providing more sources of farmers" income (Chen, Hu 1994; Li 2010).

In order to promote agriculture and rural development, the Chinese government has recently adopted a series of measures such as the 2006 New Countryside Development Programme under an umbrella framework of integrated urban-rural development. The implementation of this policy initiative has involved a number of specific mechanisms, including "urban agriculture". ${ }^{1}$ Farmers have also enthusiastically explored new ways of increasing their incomes by catering for urban market preferences, by for example, growing more green organic food and providing recreational services. A recent study of agro-tourist enterprises in Beijing showed that 90 per cent of peri-urban farm incomes came from tourism (Yang et al. 2010).

Beijing Municipality, one of the fastest growing cities in China, was our study area. In 1978 to 2010 the urban population increased from 55 per cent to 85 per cent. Beijing's situation in 1978 and its subsequent agricultural development reflect several successive transformations in China's and in Beijing's agriculture.

In the first phase, largely from the foundation of Communist China until 1978, "State monopoly purchase and selling" (Tougoutongxiao, 1949-1978) prevailed. In that period, China was an economically under-developed planned economy characterised by shortages of goods, particularly food. Agriculture, from the production and processing of food to the allocation of food to consumers, was under strict government control. People had to provide vouchers to buy flour, meat, eggs, sugar, and even to buy meals in restaurants. The second phase was one of Rural Economy reform lasting from 1978 until 1992. Agricultural productivity was dramatically enhanced, indicated by the increased share of agriculture in the Municipal Gross Domestic Product (MGDP) and rising agricultural output value (Fig. 1). The third phase lasting from

\footnotetext{
1 Urban agriculture emerged in China in the 1990s, especially in large city regions such as Beijing, Shanghai, Tianjin, Chengdu and Wuhan. It became a key factor in stimulating rural-urban integration in China through the development of multifunctional agro-economies involving agro-processing and agro-tourism.
} 
1992 until the early 2000s was one in which agricultural development faced fast urban growth. Economic reform was gradually extended to the non-agricultural urban economy, with far-reaching consequences for agricultural development, as indicated by the dramatic decline of the share of agriculture in GDP, albeit with an increase in agricultural output in absolute terms, and a fall in agro-employment (Fig. 2). Many other changes, however, particularly in the structural relationships between the agro-economy and urban sectors, cannot be identified from general GDP indicators.

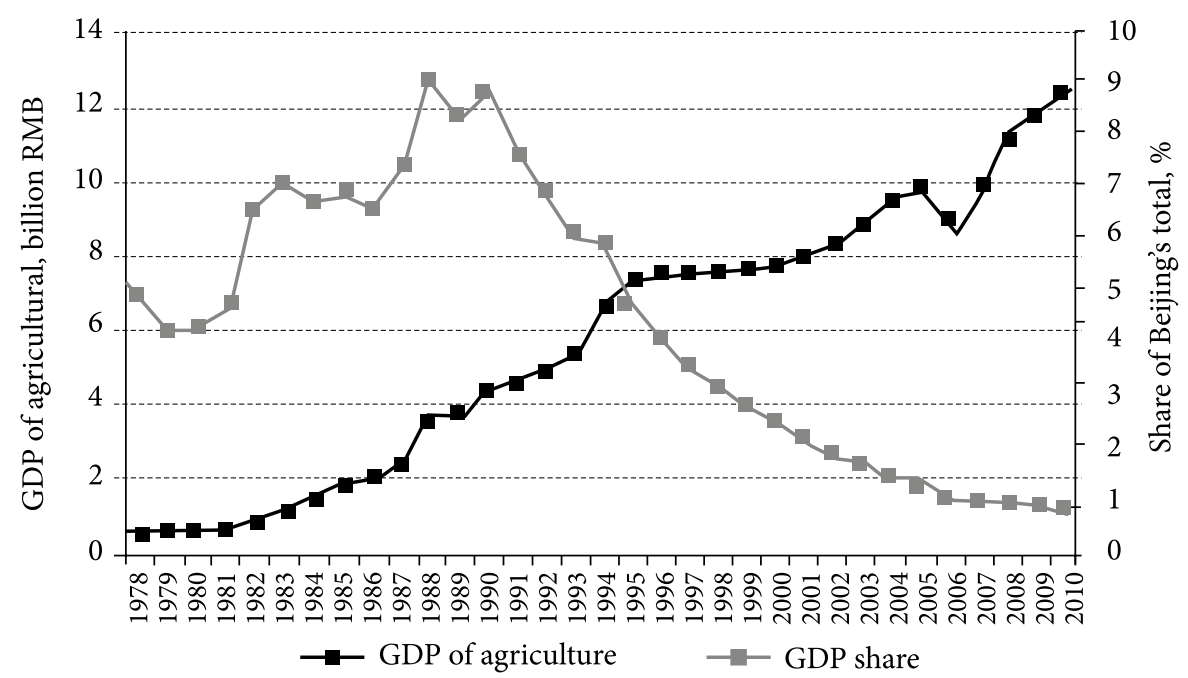

Fig. 1. Agricultural outputs and share of GDP in Beijing

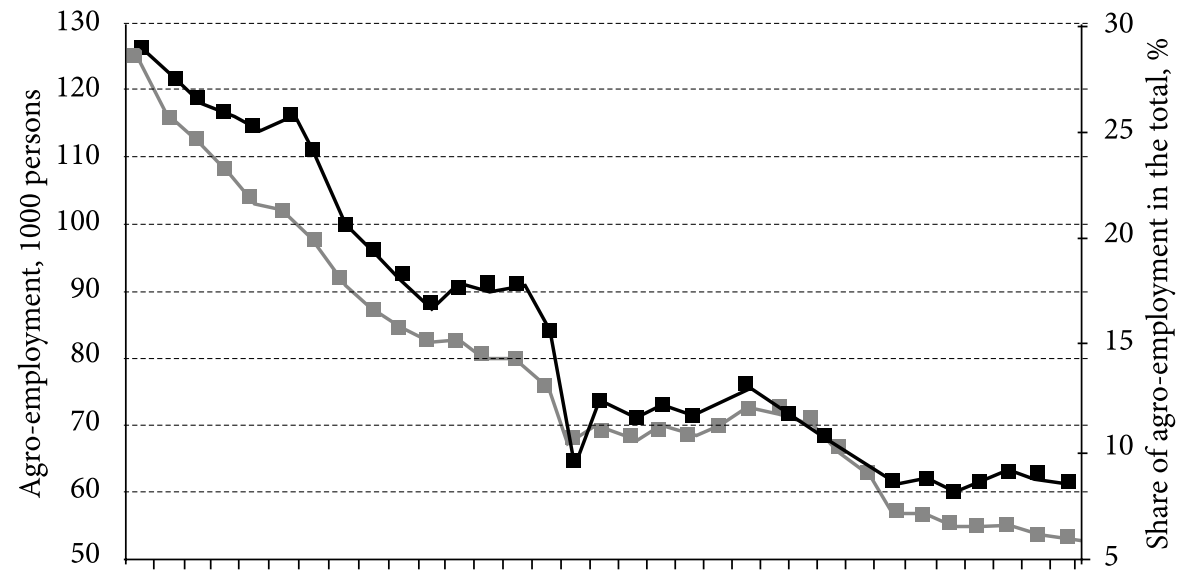

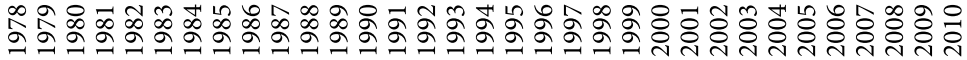

$\rightarrow-$ Agro-employment $\rightarrow$ Share of agro-employment in the total

Fig. 2. Agricultural employment in Beijing 
In the current fourth phase the Beijing Municipal Government is encouraging a more productive and equitable integration of the urban and rural components of the economy. Needing to feed a surging urban population (Beijing Municipality's population was 19.6 million according to 2010 Census) while being sensitive to increasing social and environmental pressures, the Municipal Government paid serious attention to improving agricultural production. Particularly after 2000, in order to pursue harmonious social development, a number of measures were implemented. Among these, the most important ones include the Urban Agriculture Development Scheme, High Tech Agriculture Promotion, the New Countryside Development Programme and the Key Small Town Development. These policies aim to increase agricultural profits, enhance farmers' incomes and realise prosperity in rural areas. Compared to previous measures, current policy emphases have shifted from promoting agriculture itself to establishing a platform to strengthen the synergy between rural and urban development. For example, the Urban Agriculture Scheme is based on enhancing agricultural development by taking advantage of the fast and relatively sophisticated urban development in Beijing, which provides advanced technology and diversified markets for agriculture.

\section{Methodology}

\subsection{Data}

The dependence of agriculture on urban economies (with a proxy of urban or non-agricultural sectors) can be understood through Input-Output (I-O) analysis. The I-O table is provided by Beijing Statistical Bureau, which records local inter-sectoral transactions in Beijing. To date, 5 complete surveys are available: 1987, 1992, 1997, 2002 and 2007. The industrial classification is at the 2-digit level of Chinese classification, as detailed as information at the 2- or 3-digit level of the International Standard Industrial Classification (ISIC) of the United Nations.

The sectors were grouped into agricultural and non-agricultural industries. Accordingly, the intermediate transactions were decomposed into four parts showing the supply and demand relationships of agricultural sectors with non-agricultural sectors (Fig. 3). Final demand is equal to the value of the goods and services for each row or industry that are consumed by households (farmers and citizens) and governments, that contribute to gross inventory accumulation or are accumulated as fixed assets plus exports less imports. Reflecting the particular characteristics of a socialist market economy, the Beijing I-O table also records the value of the goods and services that were transferred as a result of government orders in and out of Beijing as a part of final demand. Gross capital formation was separately identified in the tables for 2002 and 2007. Consistent with basic accounting, row totals in input-output tables must match column totals for each industry, and intermediate sales plus final demand must equal intermediate purchases plus value added for each industry. Fig. 3 also shows that the local I-O table can be partitioned into agricultural and non-agricultural parts. This partition is helpful in understanding the flows and dependencies (supply or demand) between agriculture and urban sectors. 


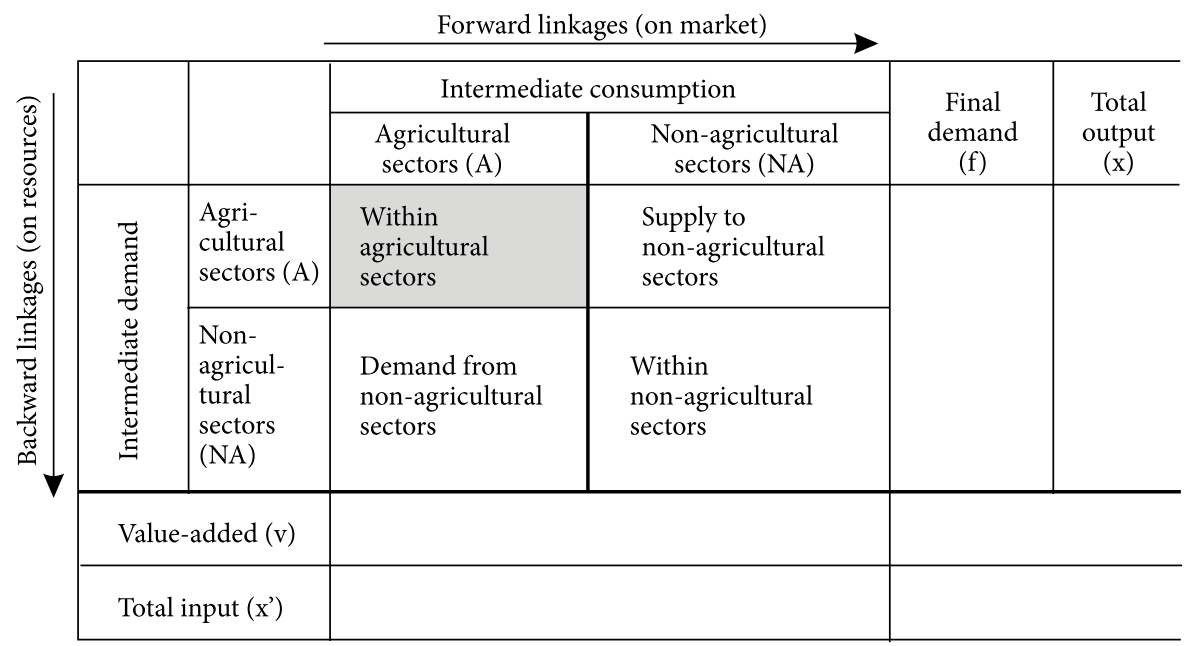

Final demand = Gross inventory accumulation + Aaccumulated fixed assets + Government purchases + farmer's consumption + citizen's consumption + Gross Capital formation + Allocate and transfer out + Export - Allocate and transfer-in-Import

Value added $=$ Depreciation + Payments to employees + Net operating surplus + Net taxes

Fig. 3. Understanding the dependence of agricultural sectors on non-agricultural sectors utilizing Beijing's input-out table

Table 1. Description of input-output data for Beijing

\begin{tabular}{clcc}
\hline \multirow{2}{*}{ Year } & \multicolumn{1}{c}{ Agricultural sectors } & \multicolumn{2}{c}{ Non-agricultural sectors } \\
\cline { 3 - 4 } & & No. of Manufacturing & No. of Services \\
\cline { 3 - 4 } 1987 & Grain crops, Other crops, Forestry, \\
\cline { 3 - 4 } 1992 & Livestock, Fishery and Other agriculture & 79 & 22 \\
\hline \multirow{2}{*}{1997} & $\begin{array}{l}\text { Crops, Forestry, Livestock, Fishery, Other } \\
\text { agriculture and Agro-services }\end{array}$ & 79 & 31 \\
\hline 2002 & $\begin{array}{l}\text { Crops, Forestry, Livestock, Fishery, and } \\
\text { Agro-services }\end{array}$ & 79 & 40 \\
\cline { 3 - 4 } 2007 & & 87 & 40 \\
\hline
\end{tabular}

Note: the sector without trades was omitted.

Table 1 summarises the way the sectors were partitioned. Of course some industrial and service activities are located in rural areas. This development can be seen as reflecting the urbanisation of the countryside. There were some changes over time in the classification of industries. Grain crops and other crops were gradually combined, and agricultural services were identified from 1997. The latter change was a response to the widening of agro-activities to include recreational demands, food tourism, etc., all of which grew in response to the growth of the urban economy of Beijing, and particularly to the rapid rise of Beijing's middle class. The overall increase in the number of services and manufacturing industries reflects increasing specialization and the increasing sophistication of the urban economy. 


\subsection{The Hypothetical Extraction Method (HEM)}

I-O accounts are of central importance in regional science in evaluating the role and nature of market interdependencies. The hypothetical extraction method (HEM) is used to extract a sector or group of sectors hypothetically from an economic system and to examine the influence of this extraction on other sectors in the economy. Compared with other I-O analyses, the HEM appropriately measures the economic linkages of a broader range of contemporary economic sectors (Kay et al. 2007). This method was originally suggested by Strassert (1968) and was developed further by Dietzenbacher and Van der Linden (1997). Recently, the HEM has attracted renewed attention in identifying and measuring the dependence of particular industries, such as energy and services, on key industries (Guerra, Sancho 2010; Temurshoev 2010).

To measure the dependencies and linkages of industries of analytical interest, the HEM simulates changes in the economic outputs of a region once the sectors under examination have hypothetically been extracted from the I-O table. This method identifies the direct, indirect and overall quantitative impact of the extracted industries on other sectors or on the economic system as a whole (Dietzenbacher, van der Linden 1997). In this research, agro-sectors were entirely or partially extracted to measure the relationship between agriculture and urban sectors. In this case the output differences before and after the hypothetical extraction reflect the linkages of the agricultural sector.

There are some variations in deployment of the HEM methodology reflecting different theoretical assumptions (Clements 1990; Heimler 1991; Sonis et al. 1995; Dietzenbacher, Van Der Linden 1997; Miller, Lahr 2001). The first main difference is whether row and column sectors are simultaneously extracted from input-output tables. The second is whether the intermediate trades of the sectors under investigation are eliminated from input-output tables or designated as zeros (Dietzenbacher, Van Der Linden 1997).

Since economic transactions are increasingly not confined to a particular geographical place, economic activities might still exist even without local trades. For example, inputs to agricultural production can be directly obtained from outside the city region. Likewise, agro-products are often transported to other regions. The extracted agro-sector coefficients should therefore be designated as zeros, rather than omit the sectors from the I-O Table. In addition, backward and forward linkages were distinguished to diagnose the supply and market dependencies of agriculture on urban economies. Row and column vectors were accordingly separately extracted from the I-O table.

Specifically, in an I-O model, if $a_{i j}$ denotes the input from sector $i$ of sector $j$, and $x_{j}$ denotes the output of sector $j, P$ is the $(n \times n)$ direct input coefficient matrix, whose elements, $p_{i j}=a_{i j} / x_{j}$, provide a snapshot of the economic interconnections among sectors in an economy at a given point in time. The $n$-element vector, $x$, of sectoral gross outputs, can be derived via the Leontief inverse $(I-P)^{-1}$ and the $(n \times 1)$ vector of final demands, $f$ :

$$
x=(I-P)^{-1} f .
$$

Backward linkages were measured by the change in an economy's output if part or all the economy no longer provided goods or services to the sector under study. Extracting the sectors of interest involved constructing a direct input coefficient matrix $P(-j)$ with $p_{i j}=0$ for 
the sectors, $i$, that supplied the sectors of interest $j$. Under unchanged technical conditions and production processes, output in the "reduced" economy was found as $x(-j)=(1-P(-j))^{-1} f$. The decrease in output is an aggregate measure of an economy's loss, including direct, indirect and induced effects of the input from $i$ to $j$ disappearing, denoting the absolute value of backward linkages of sector on sector $j$ :

$$
\sum_{i=1}^{n} x_{i}-x_{i}(-j)
$$

By analogy, forward linkages were calculated by assuming that part or all of the economy no longer demanded goods or services from the sector under study. If $S$ denotes the output coefficient matrix $s_{i j}=\frac{a_{i j}}{x_{i}}$ and $v$ denotes the vector of added value, then the input vector can be derived as $x^{\prime}=v(I-S)^{-1}$. Extracting the sectors of interest involved constructing a direct output coefficient matrix, $S(-i)$, in which $s_{i j}=0$ for the sectors, $j$ purchasing inputs from the sectors of interest $i$. The inputs of the "reduced" economy are given by $x(-i)^{\prime}=v(I-S(-i))^{-1}$. The absolute value of the forward dependence of sector on was:

$$
\sum_{j=1}^{n} x_{j}^{\prime}-x_{j}^{\prime}(-i)
$$

Using these methods, the dependence of agricultural sectors on urban sectors measured as Pure Backward Dependence (PBD) on non-agricultural sectors and the Total Backward Dependence (TBD) on all sectors including themselves. Suppose that the I-O table with $n$ sectors was partitioned into agricultural sectors and non-agricultural sectors $k+1, \ldots, n$. Extracting backward linkages of agricultural sectors $(m=1, \ldots, k)$ on non-agricultural sectors involved setting $p_{i j}=0$ for all $i=k+1, \ldots, n$ and $j=1, \ldots, k$. Given that absolute change is affected by the size of the sector, backward linkages were normalised by dividing the value of the sectoral output. Dividing Equation 2 by the total output of all agricultural sectors, $C$, the PBD was calculated as $\sum_{i=1}^{n}\left(x_{i}-x_{i}(-m)\right) / c \times 100$ per cent. It denotes the backward dependence of agricultural on non-agricultural sectors, relative to the agricultural output value.

Suppose, furthermore, that inputs from agro-sectors might also be obtained from outside the region, and that these inputs can be also extracted from the I-O table to approximate the total dependence of agricultural sectors on all sectors including themselves. Setting $p_{i j}=0$ for all $i=1, \ldots, n$ and $j=1, \ldots, k$, the TBD was derived as $\sum_{i=1}^{n}\left(x_{i}-x_{i}(-m)\right) / c \times 100$ per cent. Differences between TBD and PBD arise where local agro-sectors provide inputs to themselves, and reflect the Self Dependence of the Agro-economy $\left(S D A_{B}\right)$ :

$$
S D A_{B}=T B D-P B D .
$$

Likewise, Pure Forward Dependence (PFD) was calculated by normalising equation (3) to give $\sum_{j=1}^{n}\left(x_{j}^{\prime}-x^{\prime}(-m)\right) / c \times 100$ per cent setting $s_{i j}=0$, for all $i=1, \ldots, k$, and $j=k+1, \ldots, n$. Total 
Forward Dependence (TFD) was calculated as $\sum_{j=1}^{n}\left(x_{j}^{\prime}-x^{\prime}(-m)\right) / c \times 100$ per cent with $s_{i j}=0$, for all $i=1, \ldots, k$, and $j=1, \ldots, n$. A difference between TBD and PBD arises when agro-sectors output to themselves locally, indicating the self dependence of agro-economy $S D A_{F}$ :

$$
S D A_{F}=T F D-P B D .
$$

It can be proved that $S D A=T B D-P B D=T F D-P F D$ (see Appendix). This identity implies that the self-dependence of agricultural sectors was the same for backward and for forward linkages.

The HEM methodology can also be used to detect key urban sectors (Miyazawa 1976). If in partitioning an I-O table, the transactions set equal to zero are only those between a particular urban sector of interest and agro-sectors, the output of non-tested sectors is unaffected, and the dependence of the agro-economy on each urban sector can be identified as the loss of output associated with the change in pure or total linkages. Specifically, the backward dependence of agro-economy on a particular urban sector $i$ is given by $\left(x_{i}-x_{i}(-m)\right) / c \times 100$ per cent.

Finally, the SDA was further developed to estimate the dependence of the agro-economy on its own sectors and internal sectoral linkages. In this case the intermediate trades of agro-sectors were in turn set equal to zero. If, for example, agro-sector $j$ provided no inputs to all agro-sectors while all inputs from urban sectors remained the same, $\left(a_{i j}(-j)=0, j \in m\right.$, ), and the backward dependence of the agro-economy on sector $j$ is given by $\sum_{i=1}^{n}\left(x_{i}-x_{i}(-j)\right) / c \times 100$ per cent. Similarly, forward dependence is given by $\sum_{j=1}^{n}\left(x_{j}^{\prime}-x^{\prime}(-i)\right) / c \times 100$ per cent where $a_{i j}(-i)=0$, for $i \in m$. These indicators measure the extent to which the agro-economy is affected by or affect its sectors, regardless of the impact of relationships with urban sectors.

\section{Results and discussions}

\subsection{Urban and self dependencies of the agro-economy}

Fig. 4 illustrates the results of the analysis of the dependencies of agriculture on urban sectors and on itself in Beijing over the period 1987-2007. As indicated in the last section, and proved in the Appendix, the self dependence of the agricultural sector is the same for backward and for forward linkages, and so Fig. 4 only shows the pure and self dependencies.

Fig. 4 indicates significant historical changes in the relationship between agriculture and urban sectors with urban development. During the planned economy era, agricultural production was under the "order" or "command" of government and the organisation of agriculture was government determined. Agriculture was entirely planned and controlled, and had very limited direct interaction with urban economies (as these relationships were mediated through government agencies). After the initial reform years, in 1987, the agro-economy's PBD on urban sectors was weak (57 per cent), while the forward linkages were stronger with urban sectors absorbing the whole of agricultural output (111 per cent), indicating that agricultural output "matched" with the demands of the urban market under a system of "state monopoly 

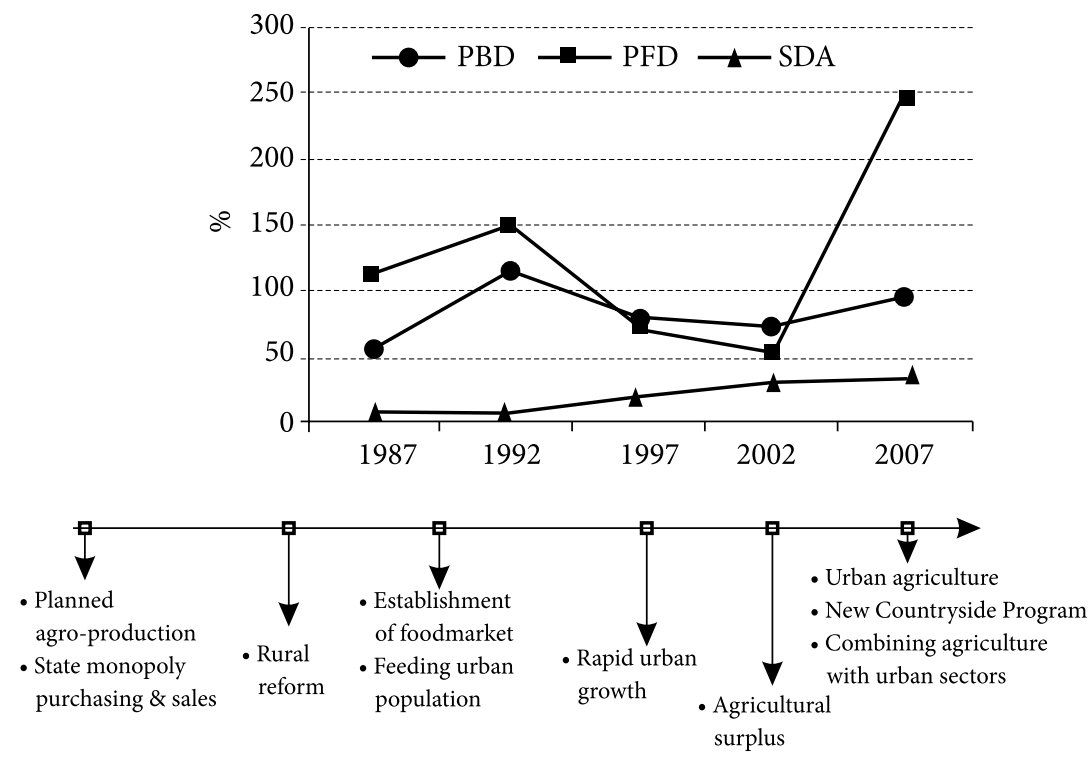

Fig. 4. Urban and self-dependencies of the agricultural sector: policy and market forces

purchase and selling". Continuing economic reform saw agricultural productivity increase, and by 1992 the value of the interaction of agriculture with urban sectors had increased, as indicated by the increase of the PBD to 116 per cent. In 1992 therefore backward dependence as measured by the PBD was greater than agricultural output, meaning that agricultural growth was heavily dependent on local inputs. A figure of less than 100 per cent may also imply that Beijing's output in terms of value was not entirely consumed by local agricultural sectors. In 1993, "state monopoly purchase and selling" was abandoned and a food market was established, encouraging the distribution and delivery of agricultural products through a real market system. One year earlier the PFD had reached 149 per cent. This increase in the PFD can be largely attributed to shortages of food, mainly vegetables and eggs. in the early 1990s. Beijing and many other Chinese cities carried out a programme for Feeding the City with Vegetable Baskets (Cailanzi) to ensure food safety, especially of fresh food and vegetables, in high demand from the surging urban population.

The subsequent falls of the PBD and PFD in 1997 and 2002 meant that the dependence of agriculture on urban sectors had declined again. The reason why was that the dominance of urban activities in the Beijing economy had steadily increased, while agriculture had relatively limited structural interactions with the urban economy yet suffered from its weak competitive position in the allocation of land, labour, etc. After 1991, there was drastic drop of the share of agricultural output in the city's economy (Fig. 1). Agriculture was relatively unattractive for producers and drew on fewer local inputs. The PBD decreased to 80 per cent in 1997 and 73 per cent in 2002. On the other hand, the overall development process, including urbanisation, increased the mobility of products, enlarging the reach and scope of suppliers. With better transportation conditions, many products and productive materials 
from other regions arrived on the Beijing market, while some of local Beijing products were shipped to other regions. In this period, China was moreover experiencing an overall surplus of agro-products. ${ }^{2}$ This surplus also contributed to the limited forward linkages of Beijing's agro-economy with the local urban market, as indicated by a PFD 72 per cent in 1997 and 54 per cent in 2002 .

After 2002, agriculture was again closely linked to urban sectors, indicating the re-establishment of a strong relationship between agriculture and urban development in Beijing. The remarkable PFD for 2007 indicates a strong dependence of agriculture on the Beijing urban market. The direct, indirect and induced outputs could be almost 2.5 times the output of the agriculture. Quite differently from reflecting the measures adopted around 1992 to ensure a sufficient quantity of food, this dependence derived from the quality of food and the provision of high-quality services such as agro-tourism (Yang et al. 2010). The PBD also increase to 97 per cent. This higher dependence on urban sectors is attributable to the increase in technology inputs and government subsidies, especially as a result of a series of policy programmes mentioned in Section 3. Driven by high operating costs, agricultural production in Beijing moved upstream along the industrial chain into activities such as horticulture and seed production. In addition, local governments subsidised agricultural production, by for example directly providing farmers with fertilisers and pesticides, strengthening some parts of agro-industrial chains. The enhancement of the dependence of agriculture on urban sectors demonstrated that agriculture can be upgraded through the establishment of closer relationships with urban markets and increased technological relationships.

Unlike the fluctuation of the PBD and PFD, the SDA of the agriculture sector steadily grew stronger and stronger. The capacity of the agricultural sector was strengthened from the early years of economic reform, with an SDA rising from 6 per cent in 1987 to 34 per cent in 2007 when urban market was relatively fully developed. This upward trend is interesting if one considers the linkages of agriculture with urban sectors. At the beginning of the development process, inputs for agriculture were mainly agricultural materials such as animal feedstock and pesticides (which we shall later consider in relation to Beijing). These inputs are however not sufficient to enhance the capacity of agriculture, as is reflected in the SDA which remains equal to 6 per cent in 1987 and 1992. In 1997 and 2002, despite lower dependence on urban sectors, as discussed above, the SDA of the agricultural increased dramatically. This increase implies that a specialisation process was under way within the agricultural sector, making the sector more adaptive to the market, and particularly to urban consumer preferences. In 2007, the SDA reached 34 per cent with more inputs of technology (the PBD was 97 per cent). Increased agricultural capacity may also be partly attributed to the introduction of new forms of agricultural organisation: in the preceding period, agro-services emerged and grew quickly, and individual farmers joined cooperatives and agro-enterprises, thereby upgrading the organisation of their agricultural activities. Consequently, the agro-economy became more similar to the urban sector in terms of modes of operation and management.

The changing dependencies of agriculture on urban sectors and itself show that agriculture was re-structured and re-positioned with the development of the urban market. The

\footnotetext{
2 After 1997, many agricultural products were in relative surplus in China (Zhou 2010; Hong 1997).
} 
analysis in this paper indicates that agriculture used to be connected with urban economies, but that the status of agriculture and of these relationships was low, involving the intensive use of inputs of traditional agricultural materials and responding to orders relating to production and distribution. Agriculture and urban activities experienced a "disconnected" period as urban sectors grew quickly and assumed positions of dominance. Subsequently, the closer interactions of agriculture and urban economies were restored with more inputs of technology and inter-relationships with other industries, such as various service sectors, strengthening the profile of agricultural development. This dynamics was also associated with self-construction of the capacity of agriculture.

\subsection{Key urban industries related to the agro-economy}

In order to look into the relationships of agriculture with urban sectors, key urban industries were examined. Table 2 identifies the backward and forward dependencies of the key industries distinguished by the existence of coefficients greater than 10 per cent in any of the years under study. In addition, tourism, finance and information services related sectors were selected for analytical interest.

Table 2. BD and FD of key industries related to the agro-economy

\begin{tabular}{|c|c|c|c|c|c|c|c|c|c|c|}
\hline & \multicolumn{5}{|c|}{ Backward dependence } & \multicolumn{5}{|c|}{ Forward dependence } \\
\hline & 1987 & 1992 & 1997 & 2002 & 2007 & 1987 & 1992 & 1997 & 2002 & 2007 \\
\hline Grain products & $2.6 \%$ & $1.3 \%$ & $4.9 \%$ & $0.3 \%$ & $0.8 \%$ & $13.5 \%$ & $7.7 \%$ & $7.6 \%$ & $1.6 \%$ & $2.3 \%$ \\
\hline Animal feedstuffs & $10.5 \%$ & $17.0 \%$ & $0.0 \%$ & $1.3 \%$ & $1.6 \%$ & $8.4 \%$ & $12.1 \%$ & $0.0 \%$ & $1.7 \%$ & $8.5 \%$ \\
\hline Meat processing & $0.2 \%$ & $0.3 \%$ & $0.0 \%$ & $0.1 \%$ & $0.1 \%$ & $15.5 \%$ & $20.7 \%$ & $13.4 \%$ & $7.3 \%$ & $32.2 \%$ \\
\hline $\begin{array}{l}\text { Other food } \\
\text { processing }\end{array}$ & $0.1 \%$ & $0.3 \%$ & $0.0 \%$ & $0.5 \%$ & $0.0 \%$ & $8.1 \%$ & $9.3 \%$ & $16.7 \%$ & $5.0 \%$ & $4.1 \%$ \\
\hline Fertilizer & $1.0 \%$ & $4.6 \%$ & $6.3 \%$ & $8.0 \%$ & $14.2 \%$ & $0.0 \%$ & $0.0 \%$ & $0.0 \%$ & $0.3 \%$ & $0.0 \%$ \\
\hline Wearing apparel & $0.1 \%$ & $0.3 \%$ & $0.1 \%$ & $0.1 \%$ & $0.1 \%$ & $6.0 \%$ & $11.4 \%$ & $1.8 \%$ & $1.0 \%$ & $3.0 \%$ \\
\hline Pesticides & $0.5 \%$ & $23.0 \%$ & $3.8 \%$ & $1.2 \%$ & $1.4 \%$ & $0.0 \%$ & $0.1 \%$ & $0.0 \%$ & $0.0 \%$ & $0.0 \%$ \\
\hline Pharmaceuticals & $0.2 \%$ & $1.1 \%$ & $1.0 \%$ & $2.8 \%$ & $1.1 \%$ & $2.7 \%$ & $2.3 \%$ & $0.7 \%$ & $4.0 \%$ & $13.0 \%$ \\
\hline $\begin{array}{l}\text { Energy and water } \\
\text { supply }\end{array}$ & $1.7 \%$ & $4.3 \%$ & $3.2 \%$ & $5.6 \%$ & $10.5 \%$ & $0.1 \%$ & $0.3 \%$ & $0.1 \%$ & $0.1 \%$ & $1.3 \%$ \\
\hline Construction & $0.0 \%$ & $0.3 \%$ & $0.3 \%$ & $0.4 \%$ & $0.4 \%$ & $1.3 \%$ & $2.6 \%$ & $0.9 \%$ & $1.8 \%$ & $9.2 \%$ \\
\hline Food services & $0.0 \%$ & $1.3 \%$ & $0.2 \%$ & $0.4 \%$ & $0.6 \%$ & $6.4 \%$ & $15.6 \%$ & $10.2 \%$ & $6.3 \%$ & $24.0 \%$ \\
\hline Hotels & $0.2 \%$ & n.a. & $0.7 \%$ & $0.8 \%$ & $1.2 \%$ & $5.3 \%$ & n.a. & $0.4 \%$ & $1.8 \%$ & $9.4 \%$ \\
\hline Finance & $1.1 \%$ & $5.9 \%$ & $4.8 \%$ & $4.8 \%$ & $1.6 \%$ & $0.0 \%$ & $1.3 \%$ & $2.3 \%$ & $1.5 \%$ & $5.0 \%$ \\
\hline Business services & $3.1 \%$ & $7.2 \%$ & $12.3 \%$ & $3.2 \%$ & $2.0 \%$ & $1.2 \%$ & $7.8 \%$ & $0.6 \%$ & $0.6 \%$ & $11.0 \%$ \\
\hline $\begin{array}{l}\text { Research \& } \\
\text { development }\end{array}$ & $0.1 \%$ & $2.2 \%$ & $1.0 \%$ & $0.5 \%$ & $0.5 \%$ & $0.2 \%$ & $0.6 \%$ & $0.1 \%$ & $0.5 \%$ & $8.3 \%$ \\
\hline $\begin{array}{l}\text { Technology } \\
\text { services }\end{array}$ & $1.7 \%$ & $5.8 \%$ & $0.9 \%$ & $0.2 \%$ & $3.2 \%$ & $0.4 \%$ & $1.1 \%$ & $0.3 \%$ & $1.1 \%$ & $8.0 \%$ \\
\hline
\end{tabular}


Continued Table 2

\begin{tabular}{lcccccccccc}
\hline & \multicolumn{4}{c}{ Backward dependence } & \multicolumn{5}{c}{ Forward dependence } \\
\cline { 2 - 11 } & 1987 & 1992 & 1997 & 2002 & 2007 & 1987 & 1992 & 1997 & 2002 & 2007 \\
\hline $\begin{array}{l}\text { Information } \\
\text { communication }\end{array}$ & n.a. & n.a. & n.a. & $3.7 \%$ & $1.4 \%$ & n.a. & n.a. & n.a. & $1.2 \%$ & $1.7 \%$ \\
Tourism & n.a. & n.a. & $0.0 \%$ & $0.0 \%$ & $0.0 \%$ & n.a. & n.a. & $0.0 \%$ & $0.0 \%$ & $3.7 \%$ \\
Health care & $0.0 \%$ & $1.0 \%$ & $0.1 \%$ & $0.2 \%$ & $0.0 \%$ & $0.6 \%$ & $1.7 \%$ & $0.8 \%$ & $1.5 \%$ & $19.4 \%$ \\
\hline
\end{tabular}

Notes: Staple food and animal feed were separate in 1987, 1992, 2002 and 2007 but aggregate in 1997. The figure was the sum of the 2 sectors accordingly.

Table 2 indicates that agriculture has stronger forward linkages than backward linkages for the selected key urban industries. Regarding backward linkages, the important sectors shifted from food processing related sectors such as Grain Products (GP), Animal Feedstuffs (AF) and Pesticides to Energy and Water Supply (EWS). The backward dependence of agriculture on pesticides was very high in 1992 (23.0 per cent), when in order to improve agricultural productivity, pesticides were introduced and intensively used. High dependence was also due to the fact that at the start of the 1990s the price of pesticides was high as the market economy was just being established in urban areas. However, in the mid-1990s, with the gradual promotion of organic agriculture, pesticide use ceased to be encouraged, as falling backward dependence figure from 1997 onwards indicate. The same reasoning applies to the high backward dependence on animal feedstuffs during the period 1987-1992. By 1997 the backward dependence indicator had fallen sharply reflecting the increasing import of animal feedstuffs and the fact that the absence of favourable government policies for the animal feed industry.

As the years passed, agricultural production consumed much more water, electricity, and other energy sources, due to increased use of cultivation and irrigation machinery. The mechanical power used for agriculture increases from $9 \mathrm{kwh} / \mathrm{ha}$ to $14 \mathrm{kwh} / \mathrm{ha}$ (Beijing Statistical Bureau 2010). As a result, the backward dependence on EWS reached as high as 10.5 per cent in $2007 .^{3}$ The agricultural sector had a backward dependence of 12.3 per cent on Business Services in 1997, demonstrating that the trading of food and related transactions were dramatically stimulated. The high values for backward dependence on Research \& Development (R\&D) and Technology Services (TS) in 1992 were largely due to government support and inputs to improve agricultural productivity. The high 2007 value for TS reflected the fact that urban economic sectors provided increased technical backup for agriculture as well as Information and Communications (IC) inputs.

As regards forward linkages, the agro-economy was closely related to food processing. The forward dependencies of food processing related sectors were generally high during 1987-1992, reflecting the role of the state monopoly for the purchasing and selling of food. The high 2007 value for Meat Processing (MP) (32 per cent) was indicative of the increase

3 Currently, about one-third of the water consumption of the city is accounted for by the agricultural sector (Yang et al. 2013) 
in meat consumption of citizens with higher income. Increased income was also reflected in Food Services (FS), whose index stood at 24 per cent in 2007, having increased from 15.6 per cent in 1992 . FS had a relatively low value of 6.3 per cent in 2002 , largely due to the surplus supply of produce from both Beijing and other regions.

The forward linkages also reflect some of the characteristics of the urban growth process. For example, the agro-economy had an 11.4 per cent dependence on Wearing Apparel in 1992 when the textile industry was an important urban sector. In 2007, however, it had much closer forward relations with Pharmaceuticals (13.0 per cent), Construction (9.2 per cent), Hotels (9.4 per cent), Business services (11.0 per cent), R \& D (8.3 per cent), TS (8.0 per cent) and Health Care (19.4 per cent). All of these sectors are important contemporary and emerging sectors in Beijing. There are also clear signs that the agro-economy increasingly interacts with Tourism and Finance with forward dependencies of 3.7 per cent and 5.0 per cent respectively in 2007. The foregoing trends reflect the fact that Beijing's agro-economy is increasingly being driven by, and is increasingly pursuing, qualitative rather than quantitative development alone.

Past trends in backward and forward dependencies suggest that the economic relationship between rural and urban sectors is likely to continue to reshape itself in response to changing conditions and interactions with urban sectors. The continuing increases in agricultural production costs and product prices will push agriculture to become more "localised". Earlier models of development that favoured the high quantity production of low value goods are fading in importance. Urbanisation is a key driver of these changes, as it is associated with more accessible technology and information services, frequent trading of agricultural goods (under conditions of better information), and increasing demand for high-quality food and agro-services as a result of the transformation of urban lifestyles. As a consequence of changes of this kind in context and demand, some agro industries, such as horticulture and flower growing, agro-finance, agro research \& development and agro-services, are likely to experience rapid growth.

\subsection{Internal relationships of agro-economy}

Table 3 records the average backward and forward dependencies within agro-sectors. Similar to the SDA, these indicators also increased, implying that internal agricultural chains were strengthened over the study period. Before 1992 average internal linkages were very limited. The reason why was that agricultural production was still primarily arranged in accordance with government orders, under the planned economy system, which minimized the need for internal supply-demand linkages within the agro-economy. The situation changed dramatically as market mechanisms came to play an increasingly dominant role in agricultural production and distribution.

Within the agro-economy, the crops and livestock play a crucial role on the backward side and livestock on the forward. This situation has prevailed since 1997. As Table 4 shows, in 2007, the input of crops affects 60.2 per cent, and the demand of livestock affects 72.6 per cent, of agro-economy output. These two sectors are the key drivers of agricultural growth (Fig. 5). Agro-services are emerging as another important internal sector of agriculture, but a low 
Table 3. Average internal linkages of the agro-economy

\begin{tabular}{ccc}
\hline & Average internal backward linkages & Average internal forward linkages \\
\hline 1987 & $2 \%$ & $2 \%$ \\
1992 & $2 \%$ & $3 \%$ \\
1997 & $7 \%$ & $7 \%$ \\
2002 & $13 \%$ & $10 \%$ \\
2007 & $17 \%$ & $26 \%$ \\
\hline
\end{tabular}

Table 4. Internal linkages of the agro-economy in Beijing in 2007

\begin{tabular}{lcc}
\hline & Internal backward linkage & Internal forward linkage \\
\hline Crops & $60.2 \%$ & $36.5 \%$ \\
Forestry & $4.1 \%$ & $8.9 \%$ \\
Livestock & $18.1 \%$ & $72.6 \%$ \\
Fishery & $0.1 \%$ & $2.2 \%$ \\
Agro-services & $4.9 \%$ & $8.0 \%$ \\
\hline
\end{tabular}

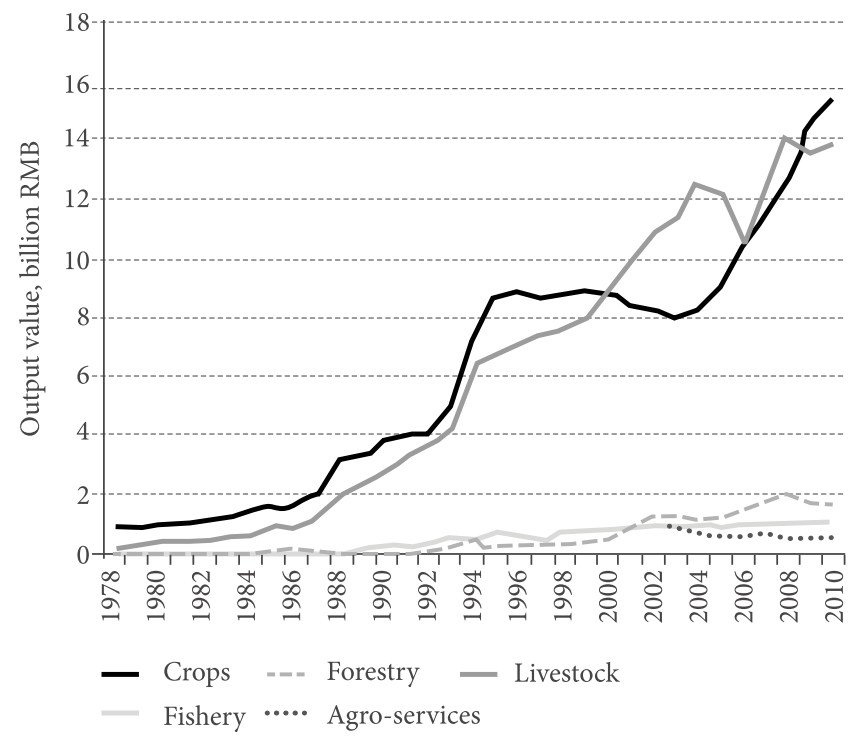

Fig. 5. Output value of agro-sectors in Beijing

level. As indicated in Fig. 5, no official data was collected for agro-services until 2003, while the output value is tended to fall slightly with a recent upturn. This relatively low output value indicates that agro-services still have a relatively small influence on the agroeconomy, although it may increase with further urban development. This analysis of internal linkages is important in that it provides an understanding of the internal flows within the 
agro-economy. It suggests that in economic terms incentive measures may have a greater impact if they target significant sectors such as crops, livestock and (maybe) agro-services.

\section{Conclusions}

The paper has analysed the relationship of agriculture with urban economies by utilizing a method based on hypothetical extractions of Input-Output (I-O) tables. The method is applied to a case study of Beijing, covering the period 1982-2007. The empirical results show the changing of the dependence of agriculture on urban sectors. In the planned economy period, agriculture was connected with urban sectors at a relatively low level with relationships centred on intensive inputs of agricultural materials and policy orders. These connections were at first gradually broken as urban economic activities came to dominate the overall development process. The relative uncompetitiveness and unattractiveness of agriculture saw the conversion of land to urban uses and decline in relative importance. Agriculture has however re-structured and re-positioned itself with the development of the urban market, the use of technological inputs, self-upgrading of management structures and methods and policy support and aids. Through these changes agriculture re-connected with urban economies but at a higher level. During this process, the capacity of agriculture was also strengthened. This more sophisticated and higher-level articulation of agriculture with urban activities, which was embodied in Beijing as new forms of agro-development such as agro-tourism, and the emerging and fast growing of agro-business. These developments drive the transformation of agriculture as a part of urban development.

This research has also identified the key urban sectors intertwined with agricultural development. These sectors, for Beijing, are food processing and food services, construction, pharmaceuticals, tourism, hotels, information and technology services, business services, finance and health care, which all have direct or indirect relationships with agriculture. As the foregoing sectors are all significantly associated with city growth, the strengthening of dependencies will reinforce the linkages between agriculture and urban economies and increasingly integrate agricultural development with the development of the urban system. Policy design should pay attention to the opportunities offered by these synergies by, for example, facilitating the development of horticulture and flower growing, agro-finance, agricultural research \& development and agro-services.

This paper also provides a significant perspective from which one can understand the dynamic relationships of agriculture with urban development. The methods used permit a deeper awareness of the complex processes of linkage of agriculture with urban development than commonly used indicators such as GDP or employment. As agro-activity is still the dominant sector in the rural economy of Beijing, 4 and also in the rest of China, an understanding of the relationships and industrial linkages between agricultural and urban sectors can largely approximate to an understanding of the relationships between rural and

\footnotetext{
${ }^{4}$ Although the rural economy is contemporarily made up of much more than agro-sectors, in China large city administrative areas, such as Beijing, Shanghai, Wuhan and Chengdu, are very large (the average territorial area is over $10,000 \mathrm{~km}^{2}$ ) and include large rural or peri-urban areas, where the agro-economy still predominates in terms of production, employment and the population it supports.
} 
urban economies. This research is therefore helpful for examining urban-rural economic relationships and is of value in relation to the design of policies for, for example, integrated urban-rural development.

The research is of course subject to certain limitations. The I-O Table for Beijing used in this study takes into account the intermediate trades within the city region without recording imports from other Chinese regions and/or imports from abroad. The research is therefore focused on local inter-industrial flows. For a complete understanding of agricultural development, imports and exports should be considered, requiring the preparation and exploration of inter-regional (provincial) I-O tables. I-O tables are static, and unable to reflect subtle changes in structure of the economy, other than through periodic comparisons of tables as in this study. More critically, I-O relationships at best reflect the relationship between agriculture and urban sectors. More disaggregated studies are needed in order to assess and understand fully overall rural - urban economic relationships, especially as non-agricultural sectors grow in importance over time in rural areas. Nevertheless, this research can be regarded as first and necessary step in achieving this objective.

\section{Acknowledgements}

The research is sponsored by China National Sciences Foundation (Grant No.41371008). The authors also like to thank Dr. Jonas Saparauskas, the Managing Editor of this journal and three anonymous fot their insightful comments and suggestions that have strengthened the pape.

\section{References}

Adeyemi, A. 2000. Urban agriculture: an abbreviated list of references and resource guide 2000, in U.S.D.O. Agriculture (ed.) Beltsville: Alternative Farming Systems Information Center, National Agricultural Library Agricultural Research Service.

Beijing Statistical Bureau. 2010. Beijing statistics yearbook. Beijing: China Statisitc Press.

Bezemer, D.; Headey, D. 2008. Agriculture, development, and urban bias, World Development 36(8): 1342-1364. http://dx.doi.org/10.1016/j.worlddev.2007.07.001

Brauers, W. K. M.; Zavadskas, E. K. 2010. Robustness in the multimoora model: the example of Tanzania, Transformations in Business \& Economics 9(3): 67-83.

Chen, J.; Hu, B. 1994. The ternary economic structure and transfer of surplux rural labor in china, Economic Studies (4): 16-18.

Clark, J. 2006. The institutional limits to multifunctional agriculture: subnational governance and regional systems of innovation, Environment and Planning C: Government and Policy 24(3): 331-349. http://dx.doi.org/10.1068/c053

Clements, B. J. 1990. On the decomposition and normalization of interindustry linkages, Economics Letters 33(4): 337-340. http://dx.doi.org/10.1016/0165-1765(90)90084-E

Dietzenbacher, E.; Van Der Linden, J. A. 1997. Sectoral and spatial linkages in the EC production structure, Journal of Regional Science 37(2): 235-257. http://dx.doi.org/10.1111/0022-4146.00053

Donald, B.; Blay-Palmer, A. 2006. The urban creative-food economy: producing food for the urban elite or social inclusion opportunity?, Environment and Planning A 38(10): 1901-1920.

http://dx.doi.org/10.1068/a37262 
Evans, N. 2010. Multifunctional agriculture: a transition theory perspective, Journal of Rural Studies 26(1): 81-82. http://dx.doi.org/10.1016/j.jrurstud.2009.10.001

FAO. 2007. Profitability and sustainability of urban and peri-urban agriculture. Rome.

Goodman, D. 2004. Rural europe redux? Reflections on alternative agro-food networks and paradigm change, Sociologia Ruralis 44(1): 3-16. http://dx.doi.org/10.1111/j.1467-9523.2004.00258.x

Guerra, A.-I.; Sancho, F. 2010. Measuring energy linkages with the hypothetical extraction method: an application to spain, Energy Economics 32(4): 831-837. http://dx.doi.org/10.1016/j.eneco.2009.10.017

Heimler, A. 1991. Linkages and vertical integration in the chinese economy, The Review of Economics and Statistics 73(2): 261-267. http://dx.doi.org/10.2307/2109516

Higgins, B. 1956. The "dualistic theory" of underdeveloped areas, Economic Development and Cultural Change 4(2): 99-115. http://dx.doi.org/10.1086/449706

Hirschman, A. 1958. The strategy of economic development. New York: W. W. Norton.

Hoggart, K.; Paniagua, A. 2001. What rural restructuring?, Journal of Rural Studies 17(1): 41-62. http://dx.doi.org/10.1016/S0743-0167(00)00036-X

Holmes, J. 2006. Impulses towards a multifunctional transition in rural Australia: gaps in the research agenda, Journal of Rural Studies 22(2): 142-160. http://dx.doi.org/10.1016/j.jrurstud.2005.08.006

Holmes, J. 2009. Comment: agency in facilitating the transition to a multifunctional countryside, Journal of Rural Studies 25(2): 248-249. http://dx.doi.org/10.1016/j.jrurstud.2009.02.001

Hong, Y. 1997. Structural adjustment on the condition of buyer's market, China Industrial Economy (8): $10-14$.

Kay, D. L.; Pratt, J. E.; Warner, M. E. 2007. Role of services in regional economy growth, Growth \& Change 38(3): 419-442. http://dx.doi.org/10.1111/j.1468-2257.2007.00377.x

$\mathrm{Li}, \mathrm{J}$. 2010. Rethinking to the rupture of urban and rural social structure and population adverse selection, Population Journal (1).

Liu, J.; Chen, J.; Fang, S.; Li, Q. 2008. Chinese agricultural policies in thirty years and analysis on the effects, China Population, Resources \& Environment 18(5): 1-6.

Liu, P.; Zhang, X. 2011. Investigation into evaluation of agriculture informatization level based on twotuple, Technological and Economic Development of Economy 17(1): 74-86. http://dx.doi.org/10.3846/13928619.2011.554007

Markey, S.; Halseth, G.; Manson, D. 2008. Challenging the inevitability of rural decline: advancing the policy of place in Northern British Columbia, Journal of Rural Studies 24(4): 409-421.

http://dx.doi.org/10.1016/j.jrurstud.2008.03.012

Marsden, T.; Banks, J.; Bristow, G. 2002. The social management of rural nature: understanding agrarian-based rural development, Environment and Planning A 34(5): 809-825. http://dx.doi.org/10.1068/a3427

Marsden, T.; Murdoch, J.; Morgan, K. 1999. Sustainable agriculture, food supply chains and regional development: editorial introduction, International Planning Studies 4(3): 295-301. http://dx.doi.org/10.1016/j.landusepol.2010.09.004

Mawois, M.; Aubry, C.; Le Bail, M. 2011. Can farmers extend their cultivation areas in urban agriculture? A contribution from agronomic analysis of market gardening systems around Mahajanga (Madagascar), Land Use Policy 28(2): 434-445. http://dx.doi.org/10.1016/j.landusepol.2010.09.004

Meijerink, G.; Roza, P. 2007. The role of agriculture in economic development. Wageningen.

Miller, R. E.; Lahr, M. L. 2001. A taxonomy of extractions, in M. L. Lahr (Ed.). Regional science perspectives in economic analysis. Elsevier Science, 407-441.

Miyazawa, K. 1976. Input-output analysis and the structure of income distribution. Berlin, Heidelberg, NewYork: Springer-Verlag. 
Morgan, S. L.; Marsden, T.; Miele, M.; Morley, A. 2010. Agricultural multifunctionality and farmers' entrepreneurial skills: a study of tuscan and welsh farmers, Journal of Rural Studies 26(2): 116-129. http://dx.doi.org/10.1016/j.jrurstud.2009.09.002

Mougeot, L. J. A. 2006. Growing better cities: urban agriculture for sustainable development. Ottawa: IDRC.

Noguera-Méndez, P.; Semitiel-García, M. 2011. The embeddedness of the agro-food system in the Spanish interindustrial structure, International Regional Science Review 34(1): 34-74. http://dx.doi.org/10.1177/0160017610387295

OECD. 1996. Territorial indicators of employment: focusing on rural development. Organization for Economic Co-operation and Development, Paris.

Ortiz-Miranda, D.; Pérez, O. M. M.; Faus, A. M. M. 2010. Innovative strategies of agricultural cooperatives in the framework of the new rural development paradigms: the case of the region of Valencia (Spain), Environment and Planning A 42(3): 661-677. http://dx.doi.org/10.1068/a42168

Rutten, R.; Boekema, F. 2007. Regional social capital: embeddedness, innovation networks and regional economic development, Technological Forecasting and Social Change 74(9): 1834-1846. http://dx.doi.org/10.1016/j.techfore.2007.05.012

Sonis, M.; Guilhoto, J. J. M.; Hewings, G. J. D.; Martins, E. B. 1995. Linkages, key sectors, and structural change: some new perspectives, The Developing Economies 33(3): 243-246. http://dx.doi.org/10.1111/j.1746-1049.1995.tb00716.x

Strassert, G. 1968. Zur bestimmung strategischer sektoren mit hilfe von input-output modellen, Jachrbucher fur Nationaloekonomie und Statistik 182: 211-215.

Tacoli, C. 1998. Rural-urban interactions: a guide to the literature, Environment and Urbanization 10(1): 147-167. http://dx.doi.org/10.1177/095624789801000105

Temurshoev, U. 2010. Identifying optimal sector groupings with the hypothetical extraction method, Journal of Regional Science 50(4): 872-890. http://dx.doi.org/10.1111/j.1467-9787.2010.00678.x

Wilson, G. A. 2007. Multifunctional agriculture: a transition theory perspective. CABI Publishing. http://dx.doi.org/10.1079/9781845932565.0000

Wilson, G. A. 2008. From "weak" to "strong" multifunctionality. Conceptualising farm-level multifunctional transitional pathways, Journal of Rural Studies 24(3): 367-383. http://dx.doi.org/10.1016/j.jrurstud.2007.12.010

Winter, M. 2003. Embeddedness, the new food economy and defensive localism, Journal of Rural Studies 19(1): 23-32. http://dx.doi.org/10.1016/S0743-0167(02)00053-0

Winter, M. 2005. Geographies of food: agro-food geographies - food, nature, farmers and agency, Progress in Human Geography 29(5): 609-617. http://dx.doi.org/10.1191/0309132505ph571pr

Yang, Z.; Cai, J.; Sliuzas, R. 2010. Agro-tourism enterprises as a form of multi-functional urban agriculture for peri-urban development in China, Habitat International 34(4): 374-385. http://dx.doi.org/10.1016/j.habitatint.2009.11.002

Yang, Z.; Cai, J.; Ottens, H. F. L.; Sliuzas, R. 2013. Beijing, Cities 31: 491-506. http://dx.doi.org/10.1016/j.cities.2011.07.007

Zhou, L. 2010. State owned market economy and rural finance in China, Chinese Economy [online], [cited 31 August 2010]. Available from Internet: http://118.145.4.123/cms/html/zazhi/2010nian6yuekan/ chanye/2010/0630/715.html 


\section{APPENDIX: PROVING THAT THE FORWARD AND BACKWARD SELF-DEPENDENCE OF AGRICULTURE IS EQUAL}

Following the analysis in the methodology section, the n-sector I-O input coefficient matrix can be partitioned into $\mathbf{m}$ agricultural sectors , and $\mathbf{r}$ non-agricultural sectors $k+1, \ldots, n$. That is,

$$
P=\left(\begin{array}{cc}
P_{m m} & P_{m r} \\
P_{r m} & P_{r r}
\end{array}\right) .
$$

Final demands $(f)$ and gross outputs $(x)$ can be partitioned similarly,

$$
f=\left(\begin{array}{c}
f_{m} \\
f_{r}
\end{array}\right) \text { and } x=\left(\begin{array}{c}
x_{m} \\
x_{r}
\end{array}\right) .
$$

Applying the matrix decomposition methodology (Sonis et al. (1995)), Leontief's inverse for this partitioned matrix can be expressed as:

$$
L=(I-P)^{-1}=\left(\begin{array}{cc}
I & 0 \\
\Delta_{r} P_{r m} & I
\end{array}\right)\left(\begin{array}{cc}
\Delta_{r} & 0 \\
0 & I
\end{array}\right)\left(\begin{array}{cc}
I & P_{m r} \\
0 & I
\end{array}\right)\left(\begin{array}{cc}
I & 0 \\
0 & \Delta_{r}
\end{array}\right),
$$

where $\Delta_{r}=\left(I-P_{r r}\right)^{-1}$ and $\Delta_{m}=\left(I-P_{m m}-P_{m r} \Delta_{r} P_{r m}\right)^{-1}$.

Gross output can then be derived as:

$$
\begin{aligned}
& x=\left(\begin{array}{c}
x_{m} \\
x_{r}
\end{array}\right)=(I-P)^{-1}\left(\begin{array}{c}
f_{m} \\
f_{r}
\end{array}\right)=\left(\begin{array}{cc}
I & 0 \\
\Delta_{r} P_{r m} & I
\end{array}\right)\left(\begin{array}{cc}
\Delta_{m} & 0 \\
0 & I
\end{array}\right)\left(\begin{array}{cc}
I & P_{m r} \\
0 & I
\end{array}\right)\left(\begin{array}{cc}
I & 0 \\
0 & \Delta_{r}
\end{array}\right)\left(\begin{array}{c}
f_{m} \\
f_{r}
\end{array}\right)= \\
& \left(\begin{array}{c}
\Delta_{m}\left(f_{m}+P_{m r} \Delta_{r} f_{r}\right. \\
\Delta_{r} P_{r m}\left[\Delta_{m}\left(f_{m}+P_{m r} \Delta_{r} f_{r}\right]+f_{r} \Delta_{r}\right.
\end{array}\right) .
\end{aligned}
$$

Rearranging terms, equation (7) can be expressed as:

$$
\begin{gathered}
x_{m}=\Delta_{m}\left(f_{m}+P_{m r} \Delta_{r} f_{r}\right) ; \\
x_{r}=\Delta_{r} P_{r m}\left[\Delta_{m}\left(f_{m}+P_{m r} \Delta_{r} f_{r}\right)\right]+\Delta_{r} f_{r}=\Delta_{r} P_{r m} x_{m}+\Delta_{r} f_{r} .
\end{gathered}
$$

When PBD was derived, $P_{r m}=0$. As a result $\Delta_{m}=\left(I-P_{m m}\right)^{-1}$. Gross output after the extraction for examining the pure backward dependence is:

$$
x_{b 1}=x_{m}+x_{r}=\left(I-P_{m m}\right)^{-1}\left(f_{m}+P_{m r} \Delta_{r} f_{r}\right)+\Delta_{r} f_{r} .
$$

Further, the TBD can be derived by setting $P_{r m}=0$ and $P_{m m}=0$. Then $\Delta_{m}=I$. Gross output after the extraction for examining the total backward dependence is:

$$
x_{b 2}=x_{m}+x_{r}=f_{m}+P_{m r} \Delta_{r} f_{r}+\Delta_{r} f_{r} .
$$

Applying equations (2), (4), (10), (11) and (12), the self dependence matrix of agriculture on backward linkages $S D A_{B}$ can be written as: 


$$
\begin{aligned}
& S D A_{B}=T B D-P B D=\frac{\left[\left[[(x-x)]_{b 2}-(x-x)\right]_{b 1}\right]}{C} \times 100 \%= \\
& \frac{\left[\left(x_{b 1}-x\right)\right]_{b 2}}{C} \times 100 \%=\frac{\left[\left(I-P_{m m}\right)^{-1}\left(f_{m}+P_{m r} \Delta_{r} f_{r}\right)-\left(f_{m}+P_{m r} \Delta_{r} f_{r}\right)\right.}{C} \times 100 \%= \\
& \frac{\left[\left(x_{m}-\Delta_{m}^{-1} x_{m}\right.\right.}{C} \times 100 \% .
\end{aligned}
$$

Therefore,

$$
S D A_{B}=i^{\prime} S D A_{B}=i^{\prime}(T B D-P B D)=\frac{\left[i^{\prime} x_{m}-i^{\prime} \Delta_{m}^{-1} x_{m}\right]}{C} \times 100 \%,
$$

where $i$ is a column vector with m elements equal to 1 .

Similarly, the input coefficient matrix $(S)$ can be partitioned as $\mathbf{m}$ agricultural sectors, and $\mathbf{r}$ non-agricultural sectors $k+1, \ldots, n$ :

$$
S=\left(\begin{array}{cc}
S_{m m} & S_{m r} \\
S_{r m} & S_{r r}
\end{array}\right)
$$

By using the matrix decomposition methodology, we can obtain:

$$
(I-S)^{-1}=\left(\begin{array}{cc}
I & 0 \\
\varphi_{r} S_{r m} & I
\end{array}\right)\left(\begin{array}{cc}
\varphi_{m} & 0 \\
0 & I
\end{array}\right)\left(\begin{array}{cc}
I & S_{m r} \\
0 & I
\end{array}\right)\left(\begin{array}{cc}
I & 0 \\
0 & \varphi_{r}
\end{array}\right)
$$

where $\varphi_{r}=\left(I-S_{r r}\right)^{-1}$ and $\varphi_{m}=\left(I-S_{m m}-S_{m r} \varphi_{r} S_{r m}\right)^{-1}$.

Then the gross input $\left(x^{\prime}\right)$ can be decomposed as:

$$
x^{\prime}=\left(x_{m}^{\prime}, x_{r}^{\prime}\right)=\left(v_{m}, v_{r}\right)(I-S)^{-1}=\left(v_{m}, v_{r}\right)\left(\begin{array}{cc}
I & 0 \\
\varphi_{r} S_{r m} & I
\end{array}\right)\left(\begin{array}{cc}
\varphi_{m} & 0 \\
0 & I
\end{array}\right)\left(\begin{array}{cc}
I & S_{m r} \\
0 & I
\end{array}\right)\left(\begin{array}{cc}
I & 0 \\
0 & \varphi_{r}
\end{array}\right) .
$$

In the rearranged matrix, the gross input can be written as:

$$
\begin{gathered}
x_{m}^{\prime}=\left(v_{m}+v_{r} \varphi_{r} S_{r m}\right) \varphi_{m}, \\
\left.x_{1} r^{I}=\left[v_{1} m+v_{1} r \varphi_{1} r S_{1} r m\right) \varphi_{1} m\right] S_{1} m r \varphi_{1} r+v_{1} r \varphi_{1} r .
\end{gathered}
$$

To derive PFD, $S_{m r}=0$, so that $\varphi_{m}=\left(I-S_{m m}\right)^{-1}$. Gross input after the extraction for examining the pure forward dependence is:

$$
x_{f 1}^{\prime}=x_{m}^{\prime}+x_{r}^{\prime}=\left(v_{m}+v_{r} \varphi_{r} S_{r m}\right)\left(I-S_{m m}\right)^{-1}+v_{r} \varphi_{r}
$$

Further, the TFD can be derived by setting $S_{m r}=0$ and $S_{m m}=0$. Then $\varphi_{m}=1$. Gross output after the extraction for examining the total backward dependence is:

$$
x_{f 2}^{\prime}=x_{m}^{\prime}+x_{r}^{\prime}=\left(v_{m}+v_{r} \varphi_{r} S_{r m}\right)+v_{r} \varphi_{r}
$$

Applying equations (3), (5), (15), (16) and (17), the self dependence matrix of agriculture on backward linkages $S D A_{F}$ can be written as: 


$$
\begin{aligned}
& S D A_{F}=T F D-P F D=\frac{\left[\left(x^{\prime}-x_{f 2}^{\prime}\right)-\left(x^{\prime}-x_{f 1}^{\prime}\right)\right]}{C} \times 100 \%= \\
& \left(x_{1} f 1^{T}-x_{1} f 2^{T}\right) / C \times 100 \%=\frac{\left[\left(v_{m}+v_{r} \varphi_{r} S_{r m}\right)\left(I-S_{m m}\right)^{-1}-\left(v_{m}+v_{r} \varphi_{r} S_{r m}\right)\right.}{C} \times 100 \%= \\
& \frac{\left[x_{m}^{\prime}-x_{m}^{\prime} \varphi_{m}^{-1}\right]}{C} \times 100 \% .
\end{aligned}
$$

Therefore,

$$
S D A_{F}=S D A_{F} i=(T F D-P F D) i=\frac{\left[x_{m}^{\prime} i-x_{m}^{\prime} \varphi_{m}^{-1} i\right]}{C} \times 100 \% .
$$

Allowing for the fact that $\Delta_{m}$ and $\varphi_{m}$ are similar matrices, and $\left(I-S_{m m}\right)^{-1}$ are also similar, satisfying:

$$
\Delta_{m}=\hat{x}_{m} \varphi_{m} \hat{x}_{m}^{-1}
$$

where $\hat{x}_{m}$ is a diagonal matrix with the sector m's outputs on the principal diagonal (Miller, Lahr 2001). In addition, $\hat{x}_{m}^{-1}=i$, and $\hat{x}_{m} \hat{x}_{m}^{-1}=i^{\prime}$.

In equation (13), $i^{\prime} x_{m}=\hat{x}_{m} i$, and $i^{\prime} \Delta_{m}^{-1} x_{m}=i^{\prime} \hat{x}_{m} \varphi_{m}^{-1} \hat{x}_{m}^{-1} x_{m} x=m^{\prime} \varphi_{m}^{-1} i$.

Therefore, $S D A_{B}=i^{\prime} S D A_{B}=S D A_{F} i=S D A_{F}=S D A$, where $S D A$ denotes the self-dependence of agriculture. This set of equalities implies that the self-dependence of agricultural sectors was the same for the backward and the forward linkages. That is $S D A=T B D-P B D=T F D-P F D$.

Zhenshan YANG. Assistant Professor of the Institute of Geographical Sciences and Natural Resources Research at Chinese Academy of Sciences. Doctor of Urban and Regional Planning from Utrecht University in the Netherlands. Research interests include urban and regional planning, urban strategy, industrial development.

Jianming CAI. Prof, Dr at the Institute of Geographical Sciences and Natural Resources Research at Chinese Academy of Sciences. Doctor of Urban Geography from Hong Kong University. Research interests include urban economic strategy and sustainable urban development.

Michael DUNFORD. Professor of Economic geography at the University of Sussex and Visiting Professor at the Institute of Geographical Sciences and Natural Resources Research at Chinese Academy of Sciences. He holds degrees in Geography and in Quantitative Economics from the University of Bristol. His research interests are in global economic development, inequality, and industrial, regional and urban development.

Douglas WEBSTER. Professor in the Schools of Geographical Sciences \& Urban Planning; Sustainability; and Politics \& Global Studies at Arizona State University. PhD in City Planning from University of California, Berkeley. Research interests inlcude city building in East Asia, urban sustainability, city development strategies. 